\title{
Targets of anti-endothelial cell antibodies in pulmonary hypertension and scleroderma
}

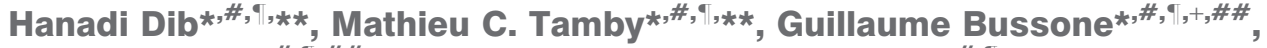

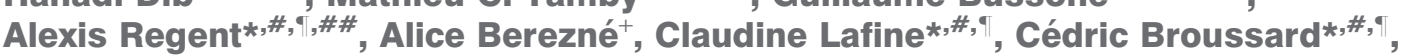 \\ Gérald Simonneau $^{\S}$, Loïc Guillevin ${ }^{+}$, Véronique Witko-Sarsat*,\#, ${ }^{\star}$, \\ Marc Humbert ${ }^{\S, f}$ and Luc Mouthon ${ }^{\star, \#, \uparrow_{,}+}$
}

ABSTRACT: Anti-endothelial cell antibodies (AECAs) have been identified in patients with systemic sclerosis (SSc) with and without pulmonary arterial hypertension (PAH) and in patients with idiopathic pulmonary arterial hypertension (iPAH). However, their target antigens remain poorly identified.

Sera from 24 patients with SSc without PAH, 20 patients with SSc with PAH, 30 with iPAH and 12 healthy controls were collected. Target antigens were identified by two-dimensional electrophoresis and immunoblotting in protein extracts of human umbilical vein endothelial cells. Targeted antigens were identified by mass spectrometry.

Serum immunoglobulin G from patients with SSc with or without PAH and patients with iPAH specifically recognised 110, 82 and 37 protein spots, respectively. Among others, target antigens of AECAs included lamin $\mathrm{A} / \mathrm{C}$, tubulin $\beta$-chain and vinculin. One-dimension immunoblotting experiments confirmed the identification of lamin $A / C$ and tubulin $\beta$-chain.

In conclusion, our results confirm the presence of AECA in patients with systemic sclerosis with and without pulmonary arterial hypertension and in those with idiopathic pulmonary arterial hypertension, and provide evidence for the identification of target antigens of these autoantibodies including lamin $\mathrm{A} / \mathrm{C}$ and tubulin $\boldsymbol{\beta}$-chain.

KEYWORDS: Autoantibodies, autoantigens, endothelial cells, pulmonary arterial hypertension, systemic sclerosis

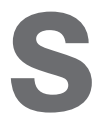
ystemic sclerosis (SSc) is a connective tissue disorder characterised by microvascular damage and excessive fibrosis of the skin and various internal organs. Although incompletely understood, the pathogenesis of SSc involves a dysregulation of endothelial cells (ECs), fibroblast dysfunction and inflammation, with altered leukocyte responses resulting in collagen overproduction [1]. Although the link between autoimmunity and tissue fibrosis is still unclear, autoantibodies to cellular components are detected in most patients with SSc [2]. Three of these autoantibodies are disease-specific and mutually exclusive: anti-centromere antibodies [3] detected in the limited cutaneous form of SSc, anti-topoisomerase 1 antibodies detected in the diffuse form of SSc [4] and anti-RNA polymerase III antibodies associated with renal crisis [5]. Other autoantibodies identified in SSc patients are directed against the nucleus and cytoplasm, membrane structures, extracellular matrix components, fibroblasts and ECs [2].
Anti-endothelial cell antibodies (AECAs) are detected in $44-84 \%$ of patients with SSc $[6,7]$ and are associated with an increased incidence of vascular manifestations [7], such as severe digital ischaemia and pulmonary arterial hypertension (PAH). PAH is characterised by a progressive increase in pulmonary vascular resistance, eventually leading to right-heart failure and premature death [8]. PAH can be idiopathic (iPAH) in the absence of other conditions or associated with diseases such as SSc. Thus, PAH develops in $~ 8-$ $12 \%$ of patients with SSc and is responsible for high mortality [9]. PAH has a multifactorial pathophysiology. The remodelling of the pulmonary vessel wall is a hallmark of severe PAH. It is marked by enhanced proliferation and survival of ECs and the formation of a layer of myofibroblasts and extracellular matrix between the endothelium and the internal elastic lamina [10].

We and others previously identified AECAs in the serum of patients with iPAH or with SSc

\section{AFFILIATIONS}

*INSERM U1016, Institut Cochin, \#CNRS UMR 8104,

"Université Paris Descartes, +Faculté de Médecine, Pôle de Médecine Interne and Centre de Référence pour les Vascularites Nécrosantes et la Sclérodermie Systémique, Hôpital Cochin, Assistance Publique-Hôpitaux de Paris, Paris,

§Université Paris Sud, Faculté de Médecine, Centre National de Référence de l'Hypertension Artérielle Pulmonaire Sévère, Service de Pneumologie et Réanimation Respiratoire, Hôpital AntoineBéclère, Assistance PubliqueHôpitaux de Paris, Clamart, and ${ }^{f}$ INSERM U999, Hypertension Artérielle Pulmonaire,

Physiopathologie et Innovation Thérapeutique, Centre Chirurgical Marie Lannelongue, Le PlessisRobinson, France.

**The two first authors contributed equally to the work.

\#\# These two authors contributed equally to the work.

\section{CORRESPONDENCE}

L. Mouthon, Institut Cochin, Pavillon Gustave Roussy, 4ème étage, Hôpital Cochin, 8 rue Méchain, 75014, Paris, France

E-mail: luc.mouthon@cch.aphp.fr

Received:

Nov 252010

Accepted after revision:

Sept 222011

First published online:

Oct 172011 
without PAH and with SSc associated with PAH (SSc-PAH) $[11,12]$. AECAs can activate ECs and induce apoptosis in SSc patients, but the pathogenic role of AECAs in patients with iPAH has not been documented. Moreover, the target antigens of AECAs in patients with SSc-PAH and iPAH remains to be identified.

We aimed to identify the target antigens of immunoglobulin (Ig)G AECAs in the sera from patients with SSc with or without $\mathrm{PAH}$ and in patients with iPAH by two-dimensional electrophoresis and immunoblotting with protein extracts of human umbilical vein ECs (HUVECs) and mass spectrometry (MS).

\section{PATIENTS AND METHODS \\ Ig sources}

Serum samples were collected from 24 patients with SSc without PAH, 20 with SSc-PAH, and 30 with iPAH. PAH was confirmed by right-heart catheterisation. In all patients with $\mathrm{PAH}$, mean pulmonary artery pressure at rest was $>25 \mathrm{mmHg}$. Serum samples from patients were tested in pools of three within the same disease group. By convention, iPAH patients excluded patients with familial or dexfenfluramine-associated PAH or any other associated condition. Patients with SSc fulfilled the American Rheumatism Association criteria [13] and/or the LeRoy and MEDSGer [14] criteria. Clinical and biological characteristics of patients are depicted in online supplementary table S1. 12 healthy blood donors (healthy controls; HCs) were recruited as controls (six males; mean \pm SD age $39.5 \pm 7.8$ yrs, range 33-61 yrs). HCs did not differ significantly from patients in age or sex. HCs had no detectable disease, no remarkable medical history and did not take any medication at the time of blood sampling. All patients and HCs were included in the Hypertension Artérielle Pulmonaire (HTAP)-Ig study (investigation and clinical research contract 2005, no. CIRC \#05066; Assistance Publique-Hôpitaux de Paris) and gave their written, informed consent to participate according to the ethics committee of Cochin Hospital, Paris, France.

\section{EC culture, protein extraction, indirect immuno- fluorescence and one-dimensional immunoblotting}

Culture, protein extraction and indirect immunofluorescence procedures with HUVECs, pulmonary (p) and dermal (d) human microvascular endothelial cells (HMVECs) are detailed in the online supplementary material.

\section{Two-dimesional electrophoresis, electro-transfer and two-} dimensional immunoblotting

HUVECs were stored at $-80^{\circ} \mathrm{C}$ in $1 \mathrm{mM}$ phenylmethyl sulphonyl fluoride and protease inhibitors (Complete Mini; Roche Diagnostics, Meylan, France). Briefly, cells were suspended at $1 \times 10^{6}$ cells $\cdot \mathrm{mL}^{-1}$ in a sample solution extraction kit (Kit 3; BioRad Laboratories, Hercules, CA, USA). Cell samples were sonicated and the supernatant was collected after ultracentrifugation (Optima L90-K ultracentrifuge; Beckman Coulter, Fullerton, CA, USA) at $150,000 \times \mathrm{g}$ for $25 \mathrm{~min}$ at $4^{\circ} \mathrm{C}$. Protein quantification was carried out using the Lowry method. The supernatant was aliquoted and stored at $-80^{\circ} \mathrm{C}$.

We used $\mathrm{pH} 3-10$ and on acrylamide gradient of $7-18 \%$ in all experiments, which allowed for studying a wide range of antigens of 10-250 kDa [15, 16]. The instrumentation and related reagents were from Bio-Rad, unless otherwise indicated.
Proteins underwent isoelectrofocusing with $17-\mathrm{cm}$ immobilised $\mathrm{pH}$ gradient (IPG) strips on the Protean IEF Cell System, essentially as described by GörG et al. [17] and reported by SERVETTAZ et al. [16]. For preparation of two-dimensional gels, $100 \mu \mathrm{g}$ of HUVEC protein extract was loaded onto IPG strips.

Prior to the second dimension of electrophoresis, the strips were equilibrated as described, then transferred to a $7-18 \%$ polyacrylamide gradient gel [16]. The equilibrated IPG gels were sealed on top of the polyacrylamide gels with use of $1 \%$ agarose containing bromophenol blue, and running buffer $(24.8 \mathrm{mM}$ Tris, $192 \mathrm{mM}$ glycine and $0.1 \%$ sodium dodecyl sulfate) was added. Gels were run initially at $40 \mathrm{~V}$ (constant) for $1 \mathrm{~h}$ and then at $80 \mathrm{~V}$ for $1 \mathrm{~h}$ and, finally, at $120 \mathrm{~V}$ for $21 \mathrm{~h} 15 \mathrm{~min}$.

The gels were transferred to polyvinylidene fluoride (PVDF) membranes (Millipore, Bedford, MA, USA) by semidry transfer (Bio-Rad) at $320 \mathrm{~mA}$ for $1 \mathrm{~h} 30 \mathrm{~min}$. After being blocked with
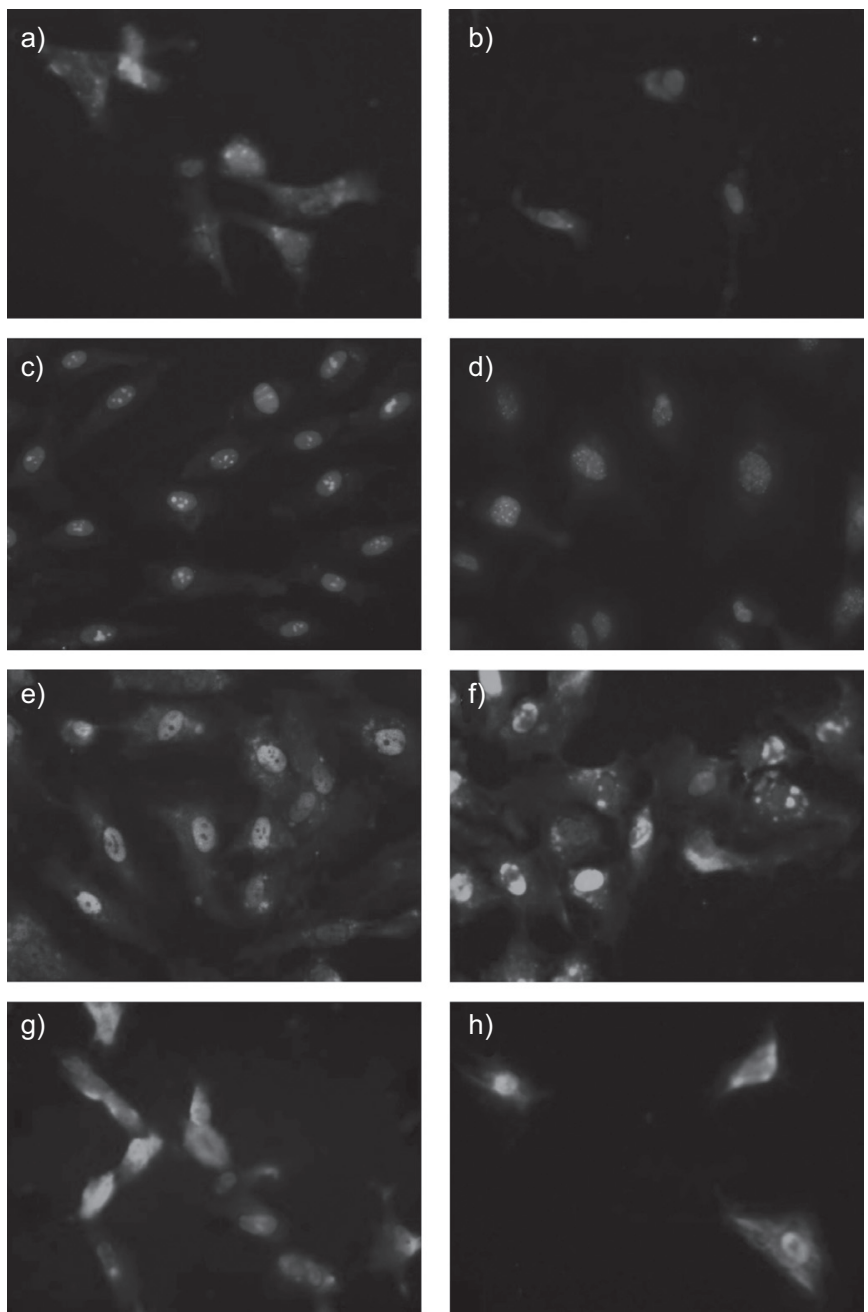

FIGURE 1. Indirect immunofluorescence on unpermeabilised human umbilical vein endothelial cells serum immunoglobulin ( $\mathrm{lg}) \mathrm{G}$ from two representative individuals from each group: $a, b)$ healthy controls, $c, d$ ) patients with systemic sclerosis without pulmonary arterial hypertension (PAH), e, f) systemic sclerosis-associated PAH and g, h) idiopathic PAH. Sera were tested at a 1:200 dilution. Secondary antibody: goat antihuman IgG antibody conjugated with fluorescein isothiocyanate nuclear staining: 4', 6diamidino-2-phenylindole (DAPI). Magnification $\times 63$. 


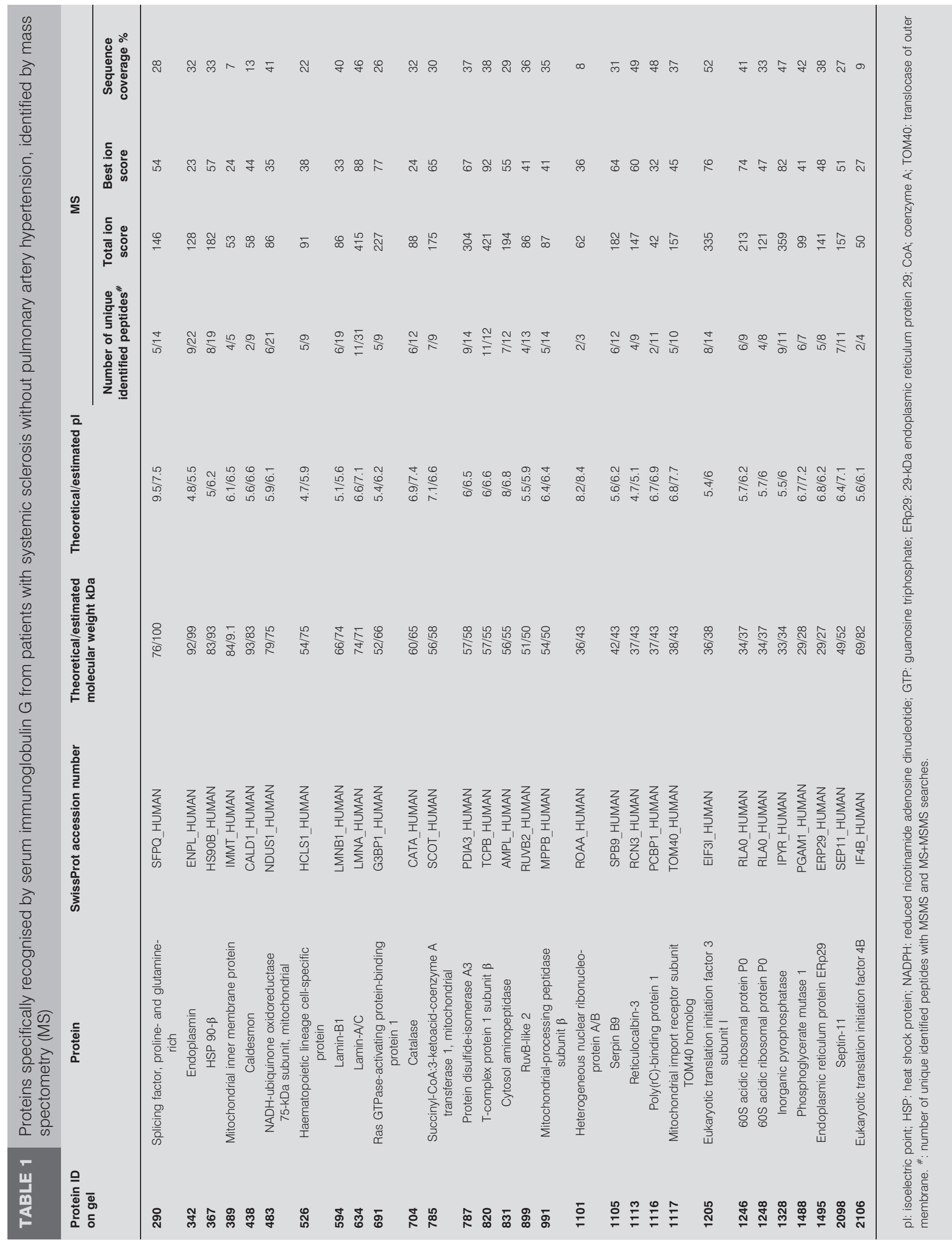


PBS- $-2.2 \%$ Tween for $90 \mathrm{~min}$, membranes were incubated overnight at $4{ }^{\circ} \mathrm{C}$ with pools of sera from three patients or the pool from $12 \mathrm{HCs}$.

IgG immunoreactivities were revealed as described [16]. Specific reactivities were determined by densitometrically scanning the membranes (densitometer GS-800; Bio-Rad) by use of Quantity One software (Bio-Rad). The membranes were then stained with colloidal gold (Protogold; British Biocell International, Cardiff, UK) and subjected to a second densitometric analysis to record labelled protein spots for each gel.

\section{Gel staining}

Analytical gels were stained with ammoniacal silver nitrate [18].

\section{Image analysis of gels and two-dimensional blots}

Images of gels and membranes were acquired by use of a densitometer (GS-800; Bio-Rad) and analysed by use of ImageMaster 2-D Platinum 5 (Amersham Biosciences, Amersham, UK) as described previously [16]. In order to maintain an objective detection of reactivities, protein spots were preselected by the analysis software using standard values of smoothing, saliency and minimal area. Each spot was confirmed by two experienced scientists (H. Dib and A. Regent). Thus, artefacts were eliminated and a threshold of intensity was determined in order to discriminate false positives. However, a visual and manual analysis was necessary to seek minor reactivities not detected by the software in order to avoid false-negative reactivities.

Only protein spots recognised by at least four different pools of three sera of patients in a given group were selected for in-gel excision and MS identification. Protein spots that were recognised by more than one group, including the group of HCs, were not selected for identification.

\section{Protein identification by MS}

Statistical analyses were used only for protein identification by mass spectrometry. The protein identification technique is detailed in the online supplementary material.

\section{RESULTS}

\section{Detection of AECAs by indirect immunofluorescence}

Using indirect immunofluorescence on unpermeabilised HUVECs, we have observed that AECAs from patients with $\mathrm{PAH}$ with or without SSc, as well as HCs, bind to the cell membranes (fig. 1). The intensity of immunofluorescence was more important in the case of patients with SSc-PAH and iPAH than in the case of patients with SSc without PAH. We have also performed indirect immunofluorescence studies using unpermeabilised $\mathrm{p}$ and $\mathrm{d}$ HMVECs (online supplementary figs S1 and S2). Interestingly, comparing reactivities of individuals in each group with HUVECs and HMVEC-p and HMVEC-d, we noted a more intense immunofluorescence for all of the groups tested with HMVEC-d, particularly in the case of patients with SSc without PAH.

\section{Two-dimensional immunoblotting of IgG reactivities from HC sera directed against HUVEC proteins}

The proteome of HUVECs contained 826 different protein spots with different isoeletric points ( $\mathrm{pI}$ ) ranging from 3 to 10 masses and from 10 to $250 \mathrm{kDa}$. Among these, a mean $\pm \mathrm{SD}$ of
$595 \pm 145$ spots were successfully transferred onto PVDF membranes (data not shown). IgG from the sera pool of 12 HCs recognised 97 protein spots (data not shown).

\section{Two-dimensional immunoblotting of IgG reactivities from sera from SSc patients without PAH directed against HUVEC protein extracts}

IgG from the seven pools of sera from SSc patients without $\mathrm{PAH}$ recognised a mean $\pm \mathrm{SD}$ of $230 \pm 100$ protein spots corresponding to 424 different protein spots. Most of these 424 spots were recognised in only one or two sera pool(s) from patients and/or HCs. 110 out of these 424 spots were specifically recognised by serum IgG from patients with SSc without PAH. 30 spots of interest were identified, corresponding to 29 different proteins (table 1). Localisation of identified spots in the analytical gel is presented in figure 2 . We found lamin A/C among the identified proteins (fig. 3).

\section{Two-dimensional immunoblotting of IgG reactivities from sera from patients with SSC-PAH}

IgG from the eight pools of sera from SSc-PAH patients recognised a mean of $202 \pm 73$ protein spots corresponding to 363 different protein spots. Most of these 363 spots were

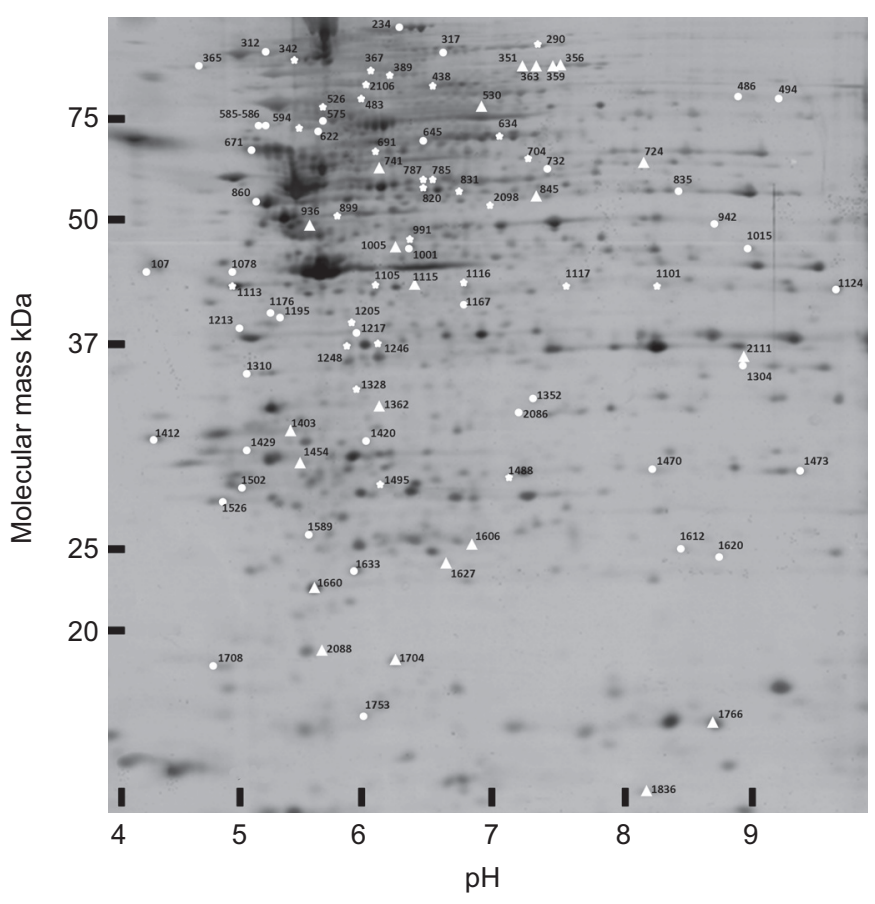

FIGURE 2. Localisation of the protein spots specifically recognised by serum immunoglobulin $(\mathrm{Ig}) \mathrm{G}$ from patients. Two-dimensional silver-stained protein spots of total protein extracted from human umbilical vein endothelial cells. First dimension ( $x$-axis): $\mathrm{pH}$ range 4-10; second dimension ( $y$-axis): acrylamide gradient varying from 7 to $18 \%$, allowing discrimination of 880 protein spots with a molecular mass range from 150 to $15 \mathrm{kDa}$. 30 protein spots were specifically recognised by serum IgG from patients with systemic sclerosis without pulmonary artery hypertension (stars), 41 protein spots specifically recognised by serum IgG from patients with systemic sclerosis with pulmonary artery hypertension (circle) and 21 protein spots specifically recognised by serum IgG from patients with idiopathic pulmonary artery hypertension (triangle). See tables 1-3 for the names of these proteins. All these protein spots were identified by mass spectrometry. 
a)
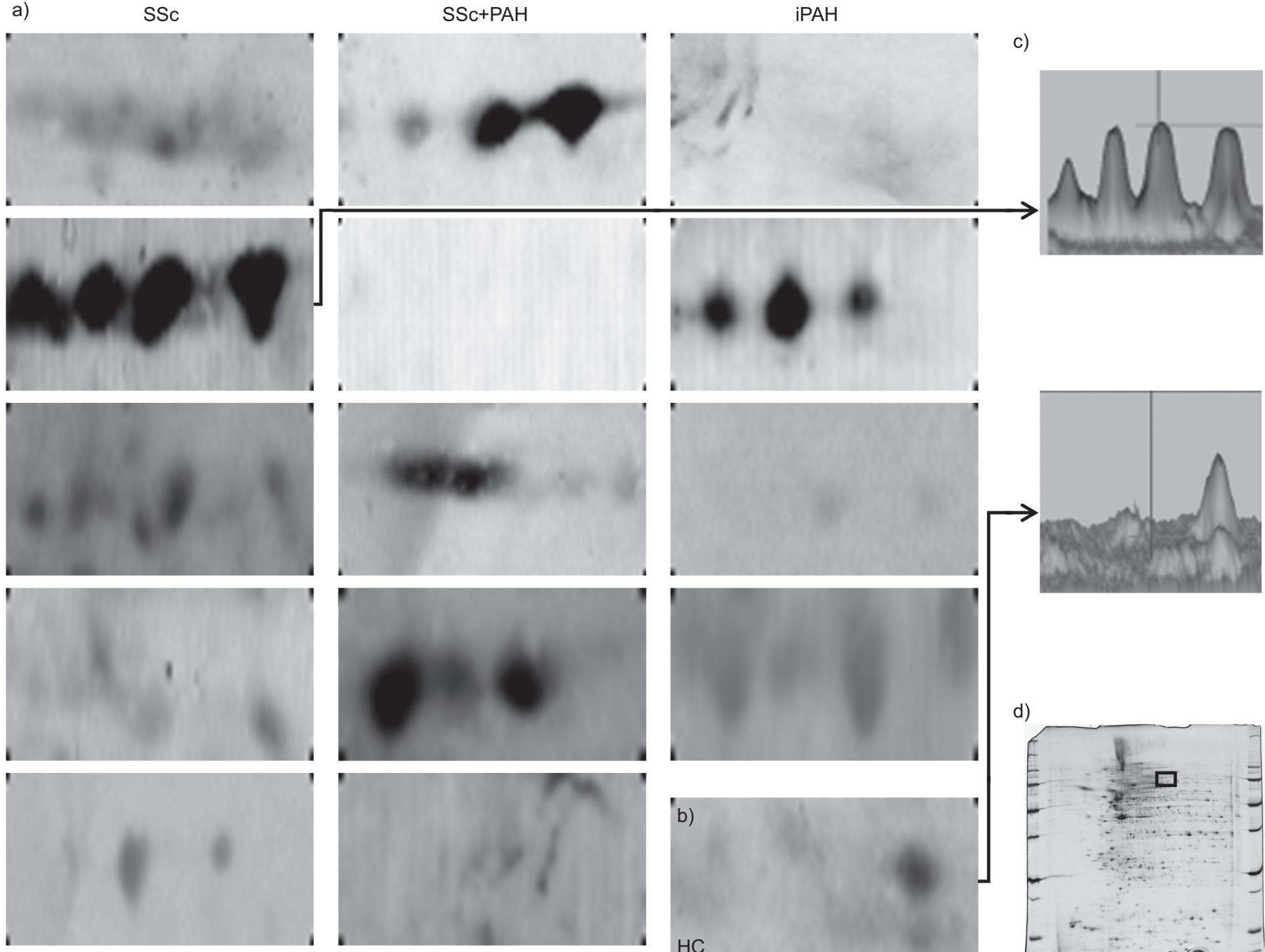

b)

d)

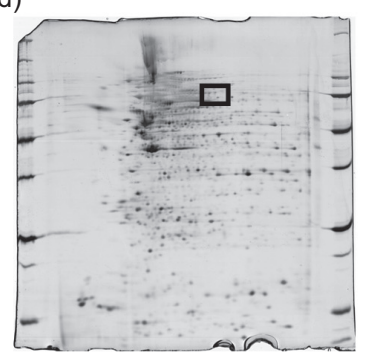

FIGURE 3. Two-dimensional immunoblots of immunoglobulin (Ig)G reactivities with lamin A/C in pools of sera from patients and healthy controls. a) IgG reactivities directed towards lamin A/C of a human umbilical vein endothelial cells (HUVECs) protein extract in five different serum pools from three systemic sclerosis (SSc) patients (left column), five serum pools from three SSc-pulmonary artery hypertension (PAH) patients (middle column) and four serum pools from three idiopathic PAH (iPAH) patients each (right column). b) IgG reactivities directed towards lamin A/C in one pool from 12 healthy controls (HC). c) Three-dimensional representation of IgG reactivity peaks towards lamin A/C in one representative sera pool from three patients (upper panel) and in the pool from the 12 healthy blood donors (lower panel). d) Two-dimensional silverstained gel of HUVECs protein extract. The area delineated by a rectangle corresponds to the region of membranes magnified in panel a) ( $\mathrm{pH} 6.8-7.5 ; 65-75 \mathrm{kDa})$.

recognised by only one or two sera pool(s) from patients with SSc-PAH and/or HCs. Among these 363 spots, 82 were specifically recognised by serum IgG from SSc-PAH patients. 43 protein spots of interest were identified corresponding to 39 different proteins (table 2). Localisation of identified spots in the analytical gel is depicted in figure 2. We found tubulin $\beta$ chain (fig. 4) and vinculin among the identified proteins.

\section{Two-dimensional immunoblotting of IgG reactivities from sera from patients with IPAH}

IgG from the 10 pools of sera from iPAH patients recognised a mean \pm SD of $111 \pm 41$ protein spots corresponding to 295 different protein spots. Most of these 295 spots were recognised by only one or two sera pool(s) from patients with iPAH and/or HCs. Among these 295 spots, 37 were specifically recognised by sera from iPAH patients. 22 protein spots of interest were identified corresponding to 22 different proteins (table 3). Localisation of identified spots in the analytical gel is depicted in figure 2. We found profilin 1 among the identified proteins.

\section{Characterisation of target antigens of AECA}

One-dimensional immunoblotting experiments were performed with HUVECs, HMVEC-p and HMVEC-d protein extracts with polyclonal antibodies raised against human recombinant lamin $\mathrm{A} / \mathrm{C}$, tubulin $\beta$-chain and vinculin. Antilamin $\mathrm{A} / \mathrm{C}$ antibodies bound to the same $70-$ and $60-\mathrm{kDa}$ proteins that were recognised by serum IgG form patients with SSc with or without PAH on HUVEC protein extract (fig. 5). Anti-tubulin antibodies bound to the same $50-$ and $40-\mathrm{kDa}$ proteins bands that were recognised by serum IgG from patients with SSc-PAH (fig. 5). Similar results were obtained with HMVEC-p and HMVEC-d protein extracts (data not 


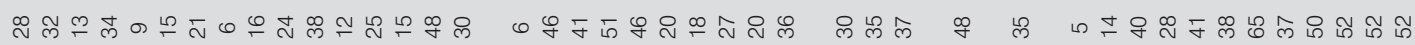

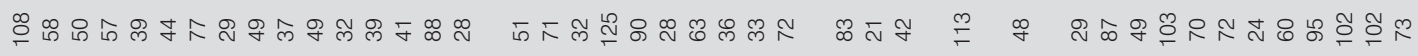

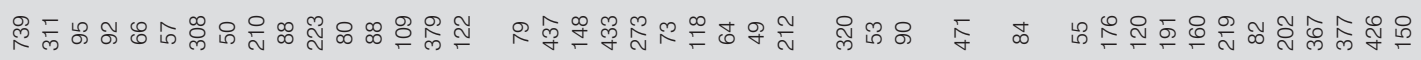

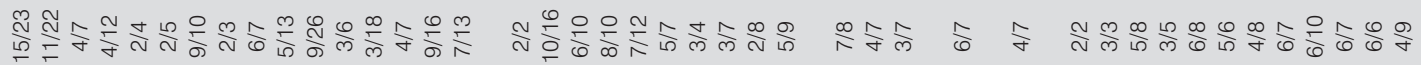

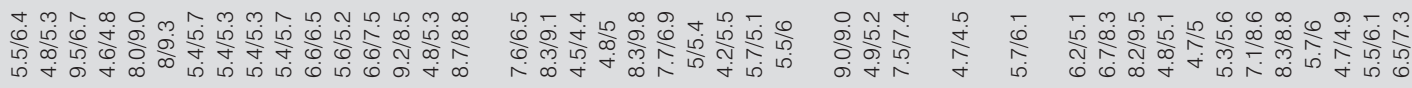

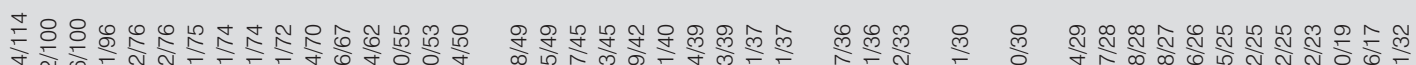

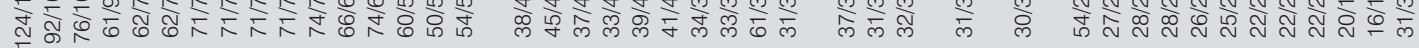

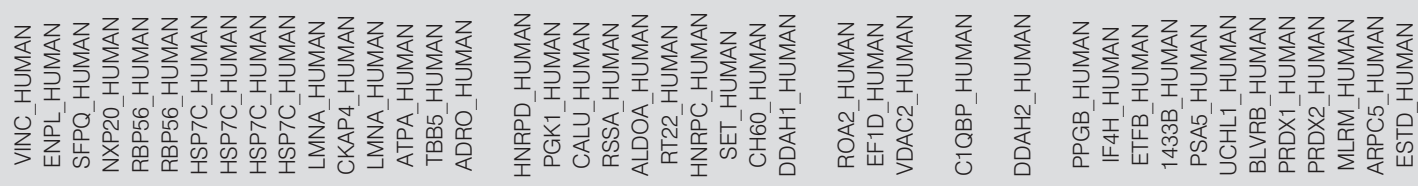

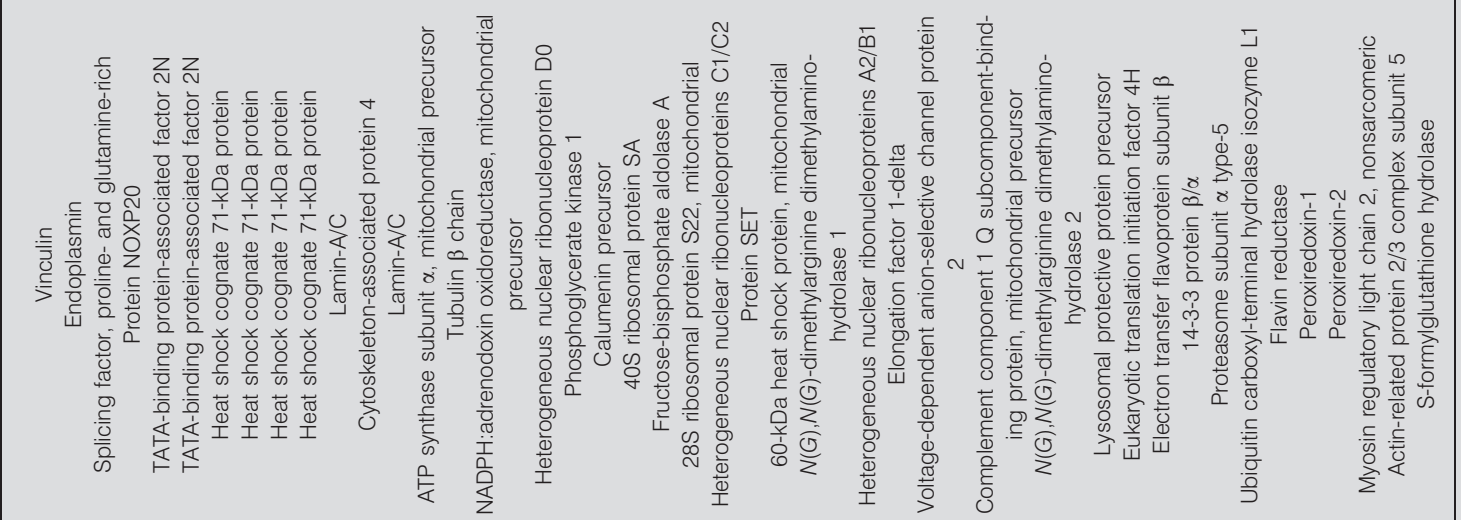

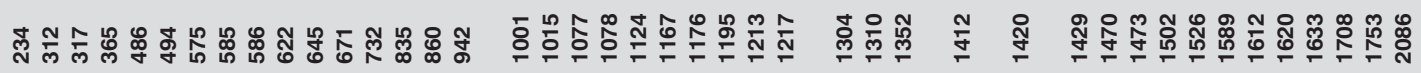


a)

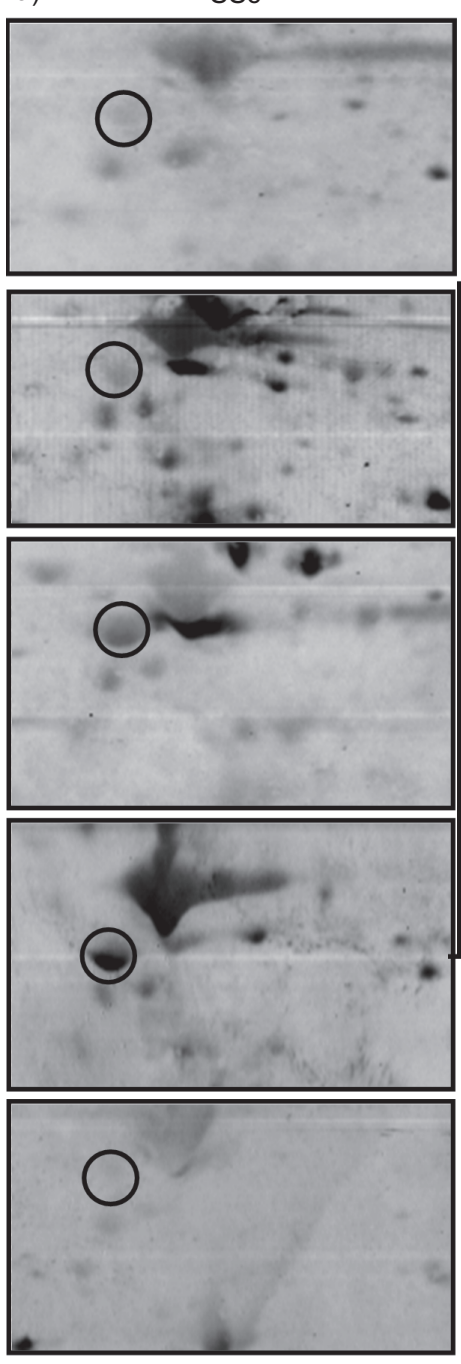

$\mathrm{SSC}+\mathrm{PAH}$
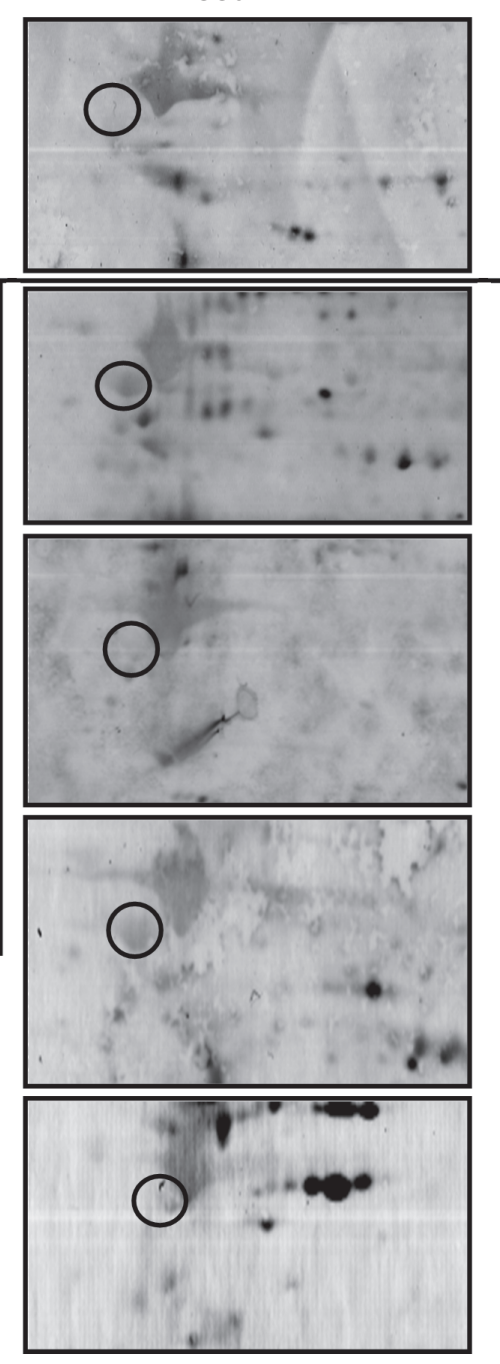

iPAH
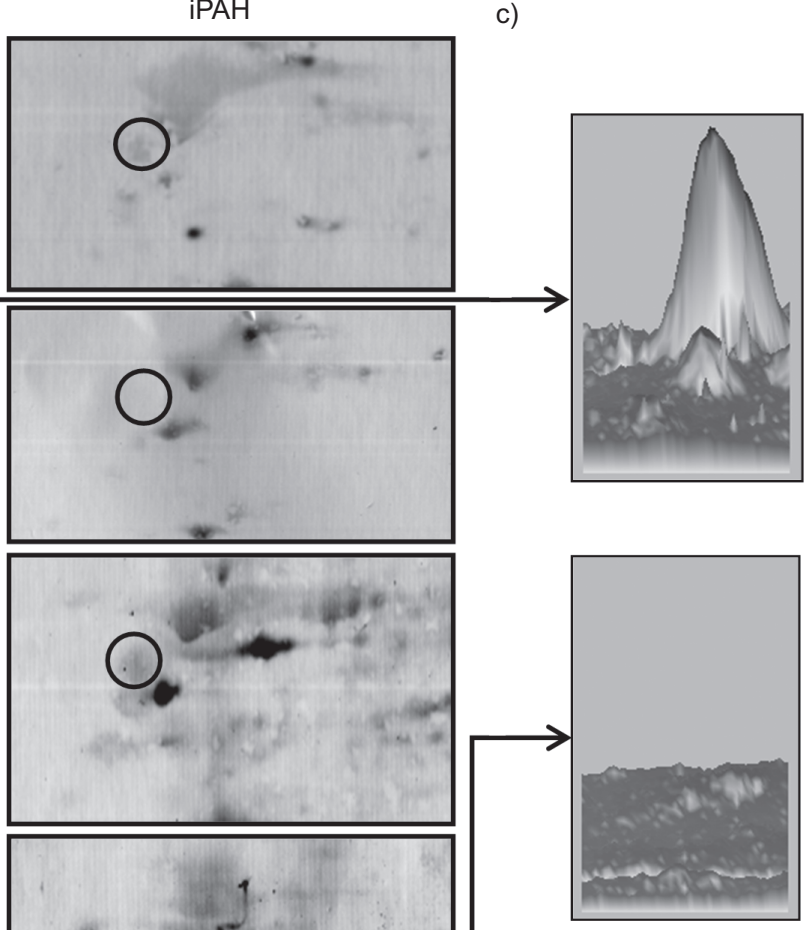

d)

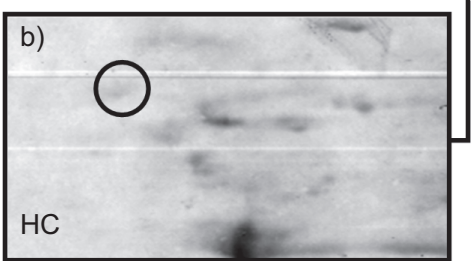

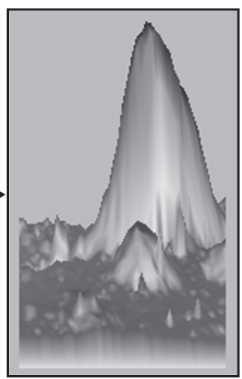

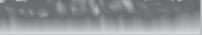

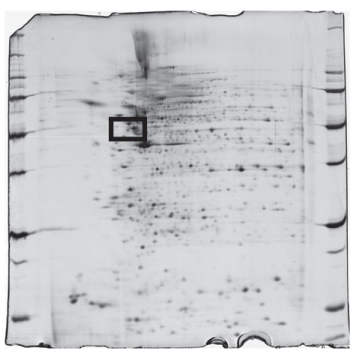

FIGURE 4. Two-dimensional immunoblots of immunoglobulin (Ig)G reactivities with tubulin in pools of sera from patients and healthy controls. a) IgG reactivities directed towards tubulin (circle) of a human umbilical vein endothelial cell (HUVEC) protein extract in five different serum pools from three systemic sclerosis (SSc) patients (left column), five serum pools from three SSc pulmonary artery hypertension (PAH) patients (middle column) and four serum pools from three idiopathic PAH (iPAH) patients (right column). b) IgG reactivities directed towards tubulin (circle) in one pool from 12 healthy controls (HC). c) Three-dimensional representation of lgG reactivity peaks towards tubulin in one representative sera pool from three patients (upper panel) and in the pool from the 12 healthy blood donors (lower panel). d) Two-dimensional silverstained gel of HUVEC protein extract. The area delineated by a rectangle corresponds to the region of membranes magnified in panel a) (pH 4.5-5.5; 50-60 kDa).

shown). Unfortunately, we failed to identify similarities between reactivities observed in individually tested patients with SSc-PAH and antibodies specific for vinculin.

\section{DISCUSSION}

We have previously reported that IgG from patients with SSc bound to DNA topoisomerase 1 [19] and centromeric protein B [20] in protein extracts of HUVECs. To our knowledge, target antigens of AECAs had never been identified before in patients with iPAH. In the present work, using a proteomic approach, we have identified target antigens of AECAs in patients with SSc with or without PAH and in patients with iPAH. Among others, target antigens of AECAs included lamin A/C, tubulin $\beta$-chain and vinculin. Additional one-dimensional immunoblotting experiments confirmed the identification of lamin A/ $\mathrm{C}$ and tubulin $\beta$-chain.
Lamins $\mathrm{A} / \mathrm{C}$ are major constituents of the inner nuclear membrane. Mutations of the LMNA gene have been identified in Hutchinson-Gilford progeria syndrome [21], which represents a major differential diagnosis of juvenile SSc. Mutant lamin A (progerin), which accumulates within the nuclei of human vascular cells, may be directly responsible for vascular involvement in progeria [22]. Anti-lamin antibodies were found in sera from patients with linear morphea [23]. In our present work, lamin A/C was identified in 15 different spots, although the different pools of sera recognised each spot with a variable intensity.

$\beta$-tubulins, along with $\alpha$-tubulin, are the major components of microtubules. $\beta$-tubulin isotype 5 has been reported as a target antigen of perinuclear anti-neutrophil cytoplasmic antibodies. Furthermore, tubulin autoantibodies are detected in several 


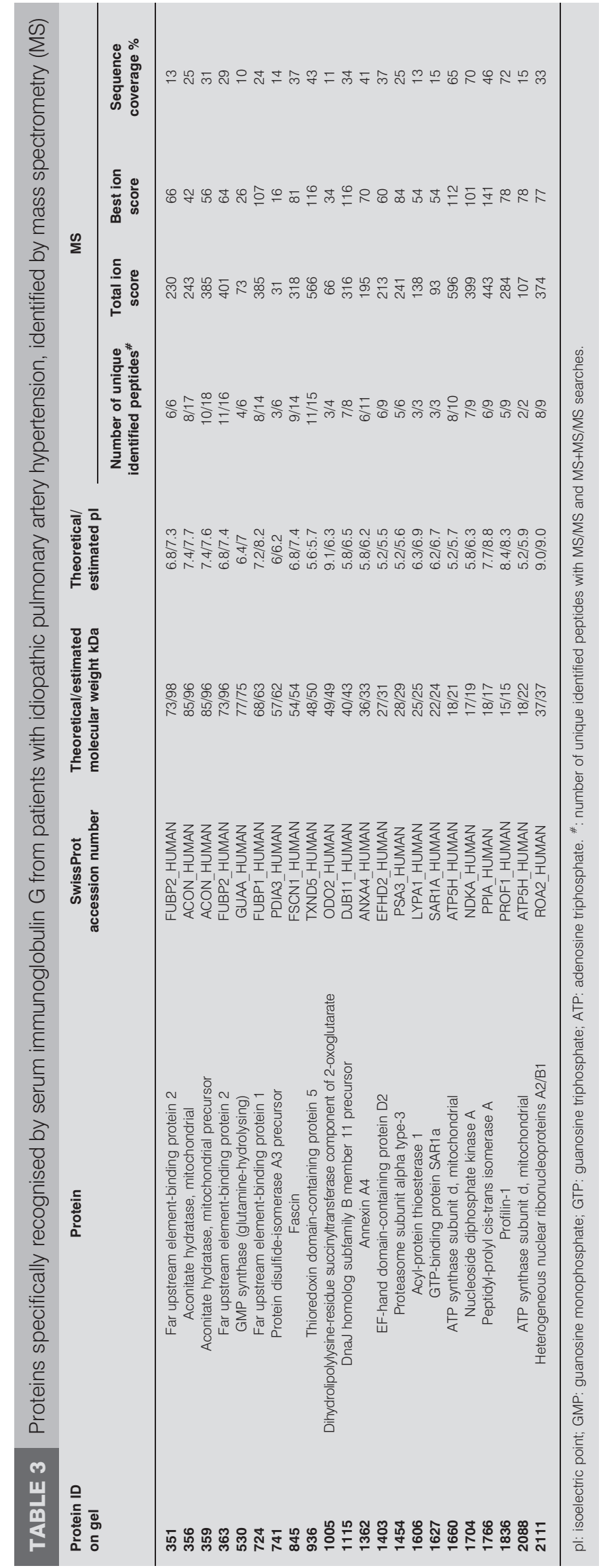

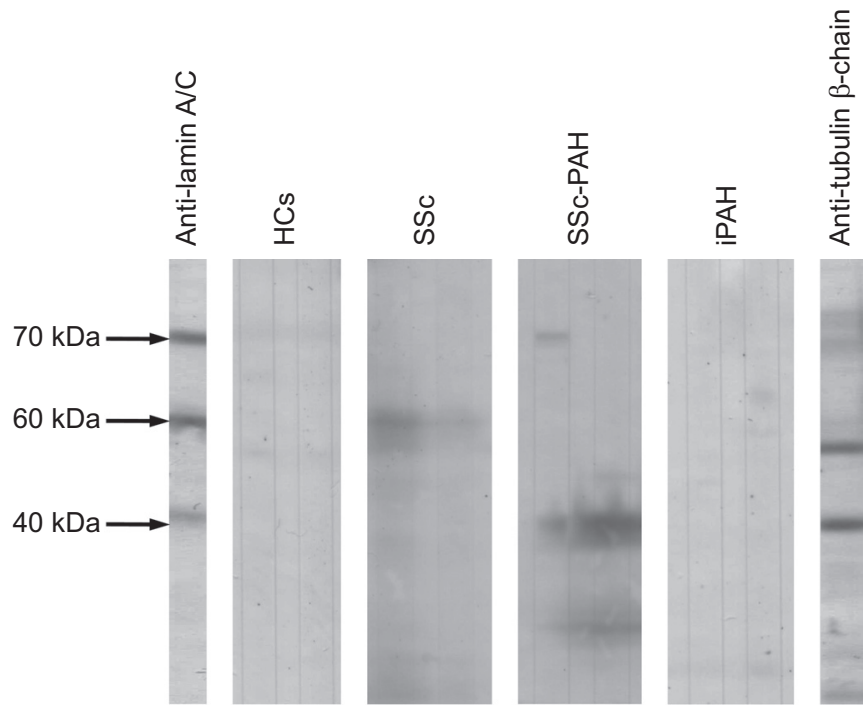

FIGURE 5. Immunoglobulin (Ig)G from patients bind to lamin $A / C$ and/or tubulin. Western blotting of serum IgG from two representative individuals from each group: healthy controls (HCs), patients with systemic sclerosis (SSc) without pulmonary artery hypertension (PAH), patients with SSc-PAH and patients with idiopathic PAH (iPAH) tested at 1:200 with protein extracts of human umbilical vein endothelial cell. Rabbit anti-lamin $A / C$ and rabbit anti-tubulin $\beta$-chain antibodies were tested at 1:200 on the same protein extract.

clinical neurological diseases, such as chronic inflammatory demyelinating polyneuropathy [24], diabetic neuropathy and systemic lupus erythematosus [25].

In SSc, many studies have suggested that AECAs could be linked to vascular injury and could reflect EC damage [26]. Whether AECAs play a role in these processes remains controversial and further work is needed. Only one study reported a correlation between the detection of AECAs in patients with SSc and the development of severe digital ischaemia and PAH [27]. As our study is descriptive and did not aim to establish a correlation between autoantibody reactivity and disease evolution, further studies are needed to document whether AECAs might help to characterise a subgroup of SSc patients at higher risk of developing vascular complications and whether AECAs might, therefore, be considered as a predictor of outcome in SSc patients. In iPAH, where disorganised proliferation and apoptosis of EC are observed [28] and lead to the formation of plexiform lesions, it would be important to investigate the role of AECAs.

Proteins identified as targets of AECAs are ubiquitous and play key roles in different cell types as they are implicated in cell morphology, metabolism and protein folding, Interestingly, we have previously reported the presence of anti-fibroblast antibodies in patients with SSc-PAH and iPAH [29] and identified that their target antigens also comprised ubiquitous proteins. Interestingly, calumenin, which is also identified in the present work as a target of AECAs in patients with SSc-PAH, is one of the targets of antifibroblast antibodies identified in patients with SSc-PAH [30].

Our work has several limitations. Thus, although the combined use of two-dimensonal electrophoresis and immunoblotting 
offers an interesting approach to identify target antigens of autoantibodies $[15,16,30]$, it does not allow targeting of membrane antigens. As expected, none of the identified antigens was located at the cell surface, because protein extraction for two-dimensional electrophoresis does not allow for identifying membrane proteins. However, using indirect immunofluorescent studies, we provide evidence that AECAs from patients and HCs bind to the EC surface. Moreover, we have used HUVECs protein extracts to identify target antigens of AECAs. EC represent a heterogeneous group of cells and there are differences between HUVECs and, for instance, HMVEC-p and HMVEC-d. We have performed indirect immunofluorescence experiments using HMVEC-p and HMVEC-d and observed a more intense immunofluorescence for patients with SSc without PAH with HMVEC-d than with HUVECs. Thus, additional experiments using HMVEC protein extracts might help to identify additional target antigens of AECAs in patients with SSc with or without PAH and iPAH patients. In addition, the total number of protein spots stained in the reference gel of the HUVEC protein extract was $<1,000$, which is less than the total number of proteins contained in these cells. Finally, our pools of sera were from three patients each because, in previous work, this number was sufficiently low to allow for detection of strong reactivity that would be present in the serum of only a single individual [30]. However, we cannot rule out that a low-intensity reactivity specific to a given individual could not be detected by this pooling approach.

In conclusion, our results confirm the presence of AECAs in patients with SSc with and without PAH and in those with $\mathrm{iPAH}$ and provide evidence for the identification of target antigens of these autoantibodies. Functional analysis will be necessary to demonstrate their potential role. The usefulness of the identified targets of AECAs for PAH or SSc screening, diagnosis or follow-up needs further confirmation by extensive laboratory screening with large groups of patients and HCs.

\section{SUPPORT STATEMENT}

H. Dib received financial support from AMPLI and ARMIIC (Association pour la Recherche en Médecine Interne et en Immunologie Clinique). M.C. Tamby received a grant from Pfizer and a Contrat d'Investigation et de Recherche Clinique (PHRC National Auto-HTAP). We thank Pfizer and the Direction de la Recherche Clinique of the Assistance Publique-Hôpitaux de Paris for supporting the project CIRC 05066, HTAP-Ig. G. Bussone received a financial support from AMPLI (Avenir Mutualiste des Professions Libérales et Indépendantes), the Société Nationale Française de Médecine Interne (SNFMI), the Fonds d'Etudes et de Recherche du Corps Médical des Hôpitaux de Paris and the Direction Régionale des Affaires Sanitaires et Sociales d'Ile-de-France. A. Regent received financial support from the Direction Régionale et Départementale des Affaires Sabitaires et Sociales de ChampagneArdennes et de la Marne and the SNFMI. We also thank the Association des Sclérodermiques de France, the Groupe Français de Recherche sur la Sclérodermie and the Unité de Recherche Clinique Paris Centre.

\section{STATEMENT OF INTEREST}

Statements of interest for M.C. Tamby, A. Berezné, L. Guillevin, G. Simonneau, M. Humbert and L. Mouthon, and for the study itself can be found at www.erj.ersjournals.com/site/misc/statements.xhtml

\section{REFERENCES}

1 Tamby MC, Chanseaud Y, Guillevin L, et al. New insights into the pathogenesis of systemic sclerosis. Autoimmun Rev 2003; 2: 152-157.

2 Gabrielli A, Moroncini G, Svegliati S, et al. Autoantibodies against the platelet-derived growth factor receptor in scleroderma: comment on the articles by Classen et al and Loizos et al. Arthritis Rheum 2009; 60: 3521-3522.

3 Moroi Y, Peebles C, Fritzler MJ, et al. Autoantibody to centromere (kinetochore) in scleroderma sera. Proc Natl Acad Sci USA 1980; 77: 1627-1631.

4 Weiner ES, Earnshaw WC, Senecal JL, et al. Clinical associations of anticentromere antibodies and antibodies to topoisomerase I. A study of 355 patients. Arthritis Rheum 1988; 31: 378-385.

5 Bunn CC, Denton CP, Shi-Wen X, et al. Anti-RNA polymerases and other autoantibody specificities in systemic sclerosis. $\mathrm{Br} \mathrm{J}$ Rheumatol 1998; 37: 15-20.

6 Rosenbaum J, Pottinger BE, Woo P, et al. Measurement and characterisation of circulating anti-endothelial cell IgG in connective tissue diseases. Clin Exp Immunol 1988; 72: 450-456.

7 Salojin KV, Bordron A, Nassonov EL, et al. Anti-endothelial cell antibody, thrombomodulin, and von Willebrand factor in idiopathic inflammatory myopathies. Clin Diagn Lab Immunol 1997; 4: 519-521.

8 Galie N, Hoeper MM, Humbert M, et al. Guidelines for the diagnosis and treatment of pulmonary hypertension. Eur Respir J 2009; 34: 1219-1263.

9 Le Pavec J, Humbert M, Mouthon L, et al. Systemic sclerosisassociated pulmonary arterial hypertension. Am J Respir Crit Care Med 2010; 181: 1285-1293.

10 Hassoun PM, Mouthon L, Barbera JA, et al. Inflammation, growth factors, and pulmonary vascular remodeling. I Am Coll Cardiol 2009; Suppl. 1, 54: S10-S19.

11 Tamby MC, Chanseaud Y, Humbert M, et al. Anti-endothelial cell antibodies in idiopathic and systemic sclerosis associated pulmonary arterial hypertension. Thorax 2005; 60: 765-772.

12 Arends SJ, Damoiseaux J, Duijvestijn A, et al. Prevalence of antiendothelial cell antibodies in idiopathic pulmonary arterial hypertension. Eur Respir J 2010; 35: 923-925.

13 Preliminary criteria for the classification of systemic sclerosis (scleroderma). Subcommittee for scleroderma criteria of the American Rheumatism Association Diagnostic and Therapeutic Criteria Committee. Arthritis Rheum 1980; 23: 581-590.

14 LeRoy EC, Medsger TA Jr. Criteria for the classification of early systemic sclerosis. J Rheumatol 2001; 28: 1573-1576.

15 Guilpain P, Servettaz A, Tamby MC, et al. A combined SDS-PAGE and proteomics approach to identify target autoantigens in healthy individuals and patients with autoimmune diseases. Ann NY Acad Sci 2007; 1109: 538-549.

16 Servettaz A, Guilpain P, Camoin L, et al. Identification of target antigens of antiendothelial cell antibodies in healthy individuals: a proteomic approach. Proteomics 2008; 8: 1000-1008.

17 Görg A, Obermaier C, Boguth G, et al. The current state of twodimensional electrophoresis with immobilized $\mathrm{pH}$ gradients. Electrophoresis 2000; 21: 1037-1053.

18 Rabilloud T. Silver staining of 2-D electrophoresis gels. Methods Mol Biol 1999; 112: 297-305.

19 Garcia de la Pena-Lefebvre P, Chanseaud Y, Tamby MC, et al. IgG reactivity with a $100-\mathrm{kDa}$ tissue and endothelial cell antigen identified as topoisomerase 1 distinguishes between limited and diffuse systemic sclerosis patients. Clin Immunol 2004; 111: 241-251.

20 Servettaz A, Tamby MC, Guilpain P, et al. Anti-endothelial cell antibodies from patients with limited cutaneous systemic sclerosis bind to centromeric protein B (CENP-B). Clin Immunol 2006; 120: 212-219. 
21 De Sandre-Giovannoli A, Bernard R, Cau P, et al. Lamin a truncation in Hutchinson-Gilford progeria. Science 2003; 300: 2055.

22 McClintock D, Gordon LB, Djabali K. Hutchinson-Gilford progeria mutant lamin A primarily targets human vascular cells as detected by an anti-Lamin A G608G antibody. Proc Natl Acad Sci USA 2006; 103: 2154-2159.

23 McKeon FD, Tuffanelli DL, Fukuyama K, et al. Autoimmune response directed against conserved determinants of nuclear envelope proteins in a patient with linear scleroderma. Proc Natl Acad Sci USA 1983; 80: 4374-4378.

24 Connolly AM, Pestronk A, Trotter JL, et al. High-titer selective serum anti- $\beta$-tubulin antibodies in chronic inflammatory demyelinating polyneuropathy. Neurology 1993; 43: 557-562.

25 Cullum NA, Coleman JW, Casson IF, et al. Antibodies to tubulin and microtubule-associated proteins. A study in diabetes mellitus, systemic lupus erythematosus, and rheumatoid arthritis. Mol Chem Neuropathol 1991; 15: 159-172.
26 Pignone A, Scaletti C, Matucci-Cerinic M, et al. Anti-endothelial cell antibodies in systemic sclerosis: significant association with vascular involvement and alveolo-capillary impairment. Clin Exp Rheumatol 1998; 16: 527-532.

27 Negi VS, Tripathy NK, Misra R, et al. Antiendothelial cell antibodies in scleroderma correlate with severe digital ischemia and pulmonary arterial hypertension. J Rheumatol 1998; 25: 462-466.

28 Nickel N, Jonigk D, Kempf T, et al. GDF-15 is abundantly expressed in plexiform lesions in patients with pulmonary arterial hypertension and affects proliferation and apoptosis of pulmonary endothelial cells. Respir Res 2011; 12: 62.

29 Tamby MC, Humbert M, Guilpain P, et al. Antibodies to fibroblasts in idiopathic and scleroderma-associated pulmonary hypertension. Eur Respir J 2006; 28: 799-807.

30 Terrier B, Tamby MC, Camoin L, et al. Identification of target antigens of antifibroblast antibodies in pulmonary arterial hypertension. Am J Respir Crit Care Med 2008; 177: 1128-1134. 